\title{
Pattern of lymphoma subtypes in a cohort of Sri Lankan patients
}

\author{
T S Waravita, S Wijetunge, N V I Ratnatunga
}

(Index words: Lymphoma, Non Hodgkin lymphoma, Hodgkin lymphoma, WHO lymphoma classification, Sri Lanka)

\begin{abstract}
Objectives To investigate the pattern of World Health Organization (WHO) lymphoma sub types in a sample from Sri Lanka.

Methods Retrospective, descriptive study was carried out using biopsy specimens of patients diagnosed or suspected to have a lymphoma received by the Department of Pathology, University of Peradeniya for WHO sub typing. A sample of 227 cases diagnosed to have a lymphoma. All lymphomas were sub classified according to WHO 2007 revised classification of haematopoietic and lymphoid neoplasm using immunohistochemistry.
\end{abstract}

Results There were 35 (15.4\%) Hodgkin Lymphoma (HL) and 192 (84.6\%) non Hodgkin Lymphoma (NHL) specimens. Of the NHL the common sub types were diffuse large B cell lymphoma 87 (38.3\%), follicular lymphoma 26 $(11.5 \%)$ and peripheral T cell lymphoma $25(11 \%)$. Of the $\mathrm{HL}$ the common sub types were mixed cellular 20 (8.8\%) and nodular sclerosis $13(5.7 \%)$. The mean age of the patients was $48.8 \pm 19.3$ years and male to female ratio was 1.4:1. The observed patterns of both $\mathrm{HL}$ and $\mathrm{NHL}$ in the study population were similar to those of other South Asian countries such as India and Pakistan.

Conclusions In the Sri Lankan sample, common sub types of lymphoma were diffuse large B cell lymphoma and follicular lymphoma. The frequency of lymphoma subtypes in the Sri Lankan sample are in accordance with the globally observed variations and similar to those observed in other South Asian countries.

Ceylon Medical Journal 2015; 60: 13-17

\section{Introduction}

Lymphoma is a diverse group of lymphoid neoplasms that comprise of Hodgkin Lymphoma (HL) and non Hodgkin Lymphoma (NHL). NHL group is particularly heterogeneous and has more than 40 different subtypes. Behaviour of these subtypes varies from low grade indolent to high grade aggressive and many of these have different treatment protocols. Therefore, sub classification of lymphoma is essential and the universally adopted classification system is the World Health Organization (WHO) Classification of Tumours of the Hematopoietic and Lymphoid Tissues [1].

The aetiology of lymphoma has not yet been fully understood and each subtype appears to have a different aetiology which may be influenced by genetic susceptibility, immune status, ethnicity, viruses, environmental factors, cultural factors and geographic factors $[1,2]$. Incidence of lymphoma subtypes is subjected to geographic and ethnic variations [2-6]. Investigation of incidence of lymphoma subtypes is important in assessing the disease burden. Observation of geographical and ethnic variations is helpful in attempts to identify the aetiology $[2,3,6]$. In South Asia, incidence of WHO subtypes of lymphoma are available only for India and Pakistan and no published reports are available for Sri Lanka. Therefore, we conducted the following study to investigate the pattern of WHO sub types of lymphoma in a sample of patients from Sri Lanka and compared them with global patterns.

\section{Methods}

This is a retrospective descriptive study of 227 lymphomas diagnosed and sub typed at the Department of Pathology, Faculty of Medicine, University of Peradeniya over the period January 2010 to May 2014. The samples were from patients treated at the Teaching Hospital, Peradeniya and referrals from other regional hospitals. Cases suspected of mycosis fungoides were received from regional skin clinics. All lymphomas were sub classified according to WHO 2007 revised classification of hematopoietic and lymphoid neoplasms using haematoxylin and eosin stain and immunohisto-chemistry [1]. The immunostains used were Leucocyte common antigen (LCA), EMA, CD 20, CD 79a, CD 3, CD 5, CD 4, CD 8, CD45RO, CD 43, CD 23, Cyclin D1, CD 10, CD 30, CD 15, CD 138, CD 68, ALK, BCL 2, TdT, and Ki 67. Age, sex and clinical presentation were obtained from the pathology request forms accompanying the biopsies. Cases diagnosed as plasmacytoma/ multilple myeloma were not included in the analysis.

A literature review was conducted to identify the global variation of lymphoma subtypes according to

Department of Pathology, Faculty of Medicine, University of Peradeniya, Sri Lanka.

Correspondence: SW, e-mail: <suwijetunge@gmail.com>. Received 22 July 2014 and revised version accepted

6 October 2014. Competing interests: none declared. 
WHO classification. For a detailed comparison, seven publications on lymphoma subtype patterns in several countries were selected, USA representing the West; India and Pakistan representing South Asia; Japan, Korea and China representing South East Asia [5, 7-12].

\section{Results}

There were 227 cases; 35 (15.4\%) were HL and 192 $(84.6 \%)$ NHLs. Among those $131(57.7 \%)$ were males and the male to female ratio was $1.4: 1$. The mean age of the sample was $48.8 \pm 19.3$ years.

Of HLs, $20(57.1 \%)$ had mixed cellular type, 13 (37.1\%) had nodular sclerosis type and the rest $(5.7 \%)$ had other types. None had nodular lymphocyte predominant HL or lymphocyte depleted classic HL sub types. The mean age of development of HL was 43.18 years \pm 21.21 (Table 1).

Of the NHLs, 148 (77.1\%) were B cell type and 44 $(22.9 \%)$ were of $\mathrm{T}$ cell or null type. High grade diffuse large B cell lymphoma which accounted for $45.3 \%$ $(87 / 192)$ was the commonest sub type. Low grade lymphoma sub types accounted for $28.1 \%$ (54/192). Of the T cell NHLs the commonest was Peripheral T cell lymphoma $(n=25) 13 \%$. The mean age of NHL was 49.83 years \pm 18.81 years. Table 1 shows the pattern of lymphoma sub types and age and sex distribution of each subtype.

Nodal disease was the presentation in $187(82.4 \%)$ and $40(17.6 \%)$ presented with extra nodal disease. Of the nodal disease, cervical lymphadenopathy 89 (39.2\%) was the commonest and generalized lymphadenopathy was present at the presentation in $19(8.4 \%)$. The commonly affected extranodal sites were skin $(n=16)$ and gastrointestinal tract $(n=5)$. Diffuse large B cedlym (Diffuse large B cell lymphoma) was the commonest type present in nodal $(86.2 \%)$ and extra nodal disease $(13.8 \%)$. Of the skin specimens 12 were mycosis fungoides and 4 were DLBL.

Table 1. Lymphoma WHO subtypes

\begin{tabular}{|c|c|c|c|c|c|}
\hline$\overline{\text { Lymphoma sub type }}$ & Frequency & Mean age in & Number of & Nodal & Extra nodal \\
\hline$N=227$ & $(\%)$ & years $(S D)$ & males (\%) & $n(\%)$ & $n(\%)$ \\
\hline \multicolumn{6}{|l|}{ Hodgkin lymphoma $n=35$} \\
\hline Nodular lymphocyte predominant & 0 & 0 & 0 & 0 & 0 \\
\hline \multicolumn{6}{|l|}{ Classic Hodgkin lymphoma } \\
\hline Mixed cellular & $20(57.1)$ & $51.82(20.9)$ & $15(75)$ & $20(100)$ & $0(0)$ \\
\hline Nodular sclerosis & $13(37.1)$ & $33.8(19.4)$ & $6(46.1)$ & $13(100)$ & $0(0)$ \\
\hline Lymphocyte rich & $1(2.9)$ & $230(0)$ & $1(100)$ & $0(0)$ & $0(0)$ \\
\hline Lymphocyte depleted & $0(0)$ & $0(0)$ & $0(0)$ & $0(0)$ & $0(0)$ \\
\hline Unclassifiable & $1(2.9)$ & 27 & $0(0)$ & $1(100)$ & $0(0)$ \\
\hline \multirow{2}{*}{\multicolumn{6}{|c|}{$\begin{array}{l}\text { Non Hodgkin lymphoma } B \\
\text { cell type } N=148\end{array}$}} \\
\hline & & & & & \\
\hline Diffuse large B cell lymphoma & $87(58.8)$ & $53.68(16.91)$ & $52(59.8)$ & $75(86.2)$ & $12(13.8)$ \\
\hline SLL/CLL & $11(7.4)$ & $49.08(17.15)$ & $6(54.5)$ & $10(90.9)$ & $1(9.1)$ \\
\hline Follicular lymphoma & $26(17.6)$ & $54.7(13.09)$ & $11(42.3)$ & $23(88.5)$ & $3(11.5)$ \\
\hline Mantle cell lymphoma & $10(6.8)$ & $52.56(11.94)$ & $7(70)$ & $9(90)$ & $1(10)$ \\
\hline Marginal zone lymphoma & $6(4)$ & $61.83(13.03)$ & $3(50)$ & $2(33.3)$ & $4(66.6)$ \\
\hline Burkitt lymphoma & $1(0.7)$ & & $1(100)$ & $0(0)$ & $1(100)$ \\
\hline Unclassifiable & $7(4.7)$ & $55.40(17.11)$ & $6(85)$ & $7(100)$ & $0(0)$ \\
\hline \multicolumn{6}{|l|}{ Non Hodgkin lymphoma $T$} \\
\hline \multicolumn{6}{|l|}{ cell /null type $N=44$} \\
\hline \multicolumn{6}{|l|}{ Anaplastic large cell lymphoma } \\
\hline ( $\mathrm{T}$ and Null type) & $6(13.7)$ & $17.33(9.89)$ & $5(83)$ & $6(100)$ & $0(0)$ \\
\hline Peripheral T cell lymphoma & $25(56.8)$ & $47.2(22.25)$ & $14(56)$ & $19(76)$ & $6(24)$ \\
\hline Mycosis fungoides & $12(27.3)$ & $29.33(13.4)$ & $4(33.33)$ & $0(0)$ & $12(100)$ \\
\hline Lymphoblastic lymphoma & $1(2.3)$ & & $1(100)$ & $1(100)$ & $0(0)$ \\
\hline
\end{tabular}


A comparison of lymphoma WHO sub type pattern in Sri Lanka with those of the USA, India, Pakistan, China, South Korea and Japan is shown in Table 2.

Table 2. Comparison of lymphoma WHO subtypes incidence patterns in the study sample (Sri Lanka), India, USA and South Korea

\begin{tabular}{|c|c|c|c|c|c|c|c|}
\hline $\begin{array}{l}\text { Lymphoma } \\
\text { WHO sub type }\end{array}$ & $\begin{array}{c}\text { Sri Lanka } \\
n(\%) \\
n=227\end{array}$ & $\begin{array}{c}\text { India }[7,8] \\
n(\%) \\
n=3224\end{array}$ & $\begin{array}{c}\text { Pakistan [9] } \\
n(\%) \\
n=246\end{array}$ & $\begin{array}{c}U S A[5] \\
n(\%) \\
n=114548\end{array}$ & $\begin{array}{c}\text { Japan [10] } \\
n(\%) \\
n=2260\end{array}$ & $\begin{array}{c}\text { Korea }[11] \\
n(\%) \\
n=5318\end{array}$ & $\begin{array}{c}\text { China [12] } \\
n(\%) \\
n=6382\end{array}$ \\
\hline \multicolumn{8}{|l|}{ Hodgkin lymphoma } \\
\hline NLPHL & 0 & $54(1.7)$ & 0 & $308(0.3)$ & $7(0.3)$ & $8(0.2)$ & $35(0.5)$ \\
\hline \multicolumn{8}{|l|}{ Classic Hodgkin } \\
\hline lymphoma & $34(15)$ & $397(12.3)$ & $66(26.7)$ & $9734(8.5)$ & $158(7.0)$ & $219(4.1)$ & $798(12.5)$ \\
\hline Mixed cellular HL & $20(8.8)$ & $142(4.4)$ & $44(17.9)$ & $1906(1.6)$ & $52(2.3)$ & $56(1.1)$ & $606(9.5)$ \\
\hline Nodular sclerosis HL & $13(5.7)$ & $116(3.6)$ & $22(8.9)$ & $6270(5.5)$ & $70(3.1)$ & $122(2.3)$ & $145(2.3)$ \\
\hline \multicolumn{8}{|l|}{ Classic Hodgkin } \\
\hline lymphoma - Other & $1(0.4)$ & $25(0.8)$ & $0(0)$ & $1558(1.4)$ & $27(1.2)$ & $16(0.3)$ & $47(0.7)$ \\
\hline Unclassified & $1(0.4)$ & $114(3.5)$ & $0(0)$ & $0(0)$ & $9(0.4)$ & $17(0.3)$ & $0(0)$ \\
\hline \multicolumn{8}{|l|}{ Non Hodgkin lymphoma } \\
\hline \multicolumn{8}{|l|}{$B$ cell type } \\
\hline \multicolumn{8}{|l|}{ Diffuse large B } \\
\hline cell lymphoma & $87(38.3)$ & $937(29.1)$ & $119(48.4)$ & $24246(21.2)$ & $746(33)$ & $1650(31)$ & $2288(35.9)$ \\
\hline \multicolumn{8}{|l|}{ small lymphocytic } \\
\hline \multicolumn{8}{|l|}{ lymphoma/chronic } \\
\hline lymphocytic leukeamia & $11(4.8)$ & $155(4.8)$ & $4(1.6)$ & $16984(14.8)$ & $32(1.4)$ & $97(1.8)$ & $256(4)$ \\
\hline Follicular lymphoma & $26(11.4)$ & $350(10.9)$ & $9(3.7)$ & $10705(9.3)$ & $413(18.3)$ & $91(1.7)$ & $327(5.1)$ \\
\hline Mantle cell lymphoma & $10(4.4)$ & $95(2.9)$ & $4(1.6)$ & $1691(1.5)$ & $61(2.7)$ & $98(1.8)$ & $175(2.7)$ \\
\hline Marginal zone lymphoma & $6(2.6)$ & $220(6.8)$ & $4(1.6)$ & $3247(2.8)$ & $127(5.6)$ & $720(13.5)$ & $355(5.6)$ \\
\hline Nodal & $2(0.8)$ & $52(1.6)$ & 0 & & $32(1.4)$ & $54(1.0)$ & $5(0.7)$ \\
\hline Extra nodal & $4(1.6)$ & $168(5.2)$ & $4(1.6)$ & & $95(4.2)$ & $661(12.4)$ & $350(5.5)$ \\
\hline Burkitt lymphoma & $1(0.4)$ & $50(1.6)$ & $7(2.8)$ & $1102(0.9)$ & $15(0.7)$ & $111(2.1)$ & $106(1.7)$ \\
\hline \multicolumn{8}{|l|}{ Non Hodgkin lymphoma } \\
\hline \multicolumn{8}{|l|}{$T$ cell type } \\
\hline \multicolumn{8}{|l|}{ Anaplastic large } \\
\hline cell lymphoma & $6(2.6)$ & $113(3.5)$ & $4(1.6)$ & $864(0.8)$ & $45(2)$ & $104(1.4)$ & $196(3.1)$ \\
\hline \multicolumn{8}{|l|}{ Peripheral T cell lymphoma } \\
\hline (not otherwise specified) & $25(11)$ & $53(1.6)$ & $10(4.1)$ & $1031(0.9)$ & $102(4.5)$ & $211(4)$ & $221(3.5)$ \\
\hline Mycosis fungoides & $12(5.2)$ & $24(0.7)$ & $5(2.1)$ & $1773(1.5)$ & $11(0.5)$ & $21(0.4)$ & $14(0.2)$ \\
\hline \multicolumn{8}{|l|}{ Adult T cell } \\
\hline leukaemia/ lymphoma & $0(0)$ & $0(0)$ & $0(0)$ & $0(0)$ & $226(10)$ & $1(0.01)$ & $0(0)$ \\
\hline $\mathrm{E} \mathrm{NK} / \mathrm{T}$ & $0(0)$ & $19(0.6)$ & $0(0)$ & $1501(1.3)$ & $36(1.6)$ & $206(3.8)$ & 949 (14.9) \\
\hline \multicolumn{8}{|l|}{ Angioimmunoblastic } \\
\hline T cell lymphoma & $0(0)$ & $28(0.9)$ & $0(0)$ & $176(0.2)$ & $115(5.1)$ & $43(0.8)$ & $185(2.9)$ \\
\hline Other types & $0(0)$ & $0(0)$ & $0(0)$ & $1502(1.1)$ & 0 & $230(4.3)$ & $0(0)$ \\
\hline Lymphoblastic lymphoma & $1(0.4)$ & $185(5.7)$ & $11(3.9)$ & $6127(5.3)^{*}$ & $21(0.9)$ & $873(16.2)$ & $301(4.7)$ \\
\hline
\end{tabular}

ENK/T - nasal extra nodal NK/T lymphoma - nasal type 


\section{Discussion}

Overall rates of lymphoma tend to be lower in Asia compared to North America, Europe and Australia [2,6] Age specific incidence rate (ASR) for USA during 20052009 was 19.6 compared to 2.4 in India, 2.1 in China and 5.1 in Japan [6]. In Sri Lanka, lymphoma ASR is 3.8 for males and 2.6 for females. Lymphoma is the 5th leading malignancy among males and 10th among females in Sri Lanka [13]. An "epidemic proportion" increase in NHL has been reported in the West since 1950s [2]. Although, HIV infection has been attributed to part of this increase, the reasons are unknown for most cases [2].

According to the present study, the most common sub type of lymphoma in the Sri Lankan sample was DLBCL in both nodal and extra nodal sites. Despite global variation in the patterns of lymphoma subtypes, DLBCL is the commonest lymphoma subtype. However, DLBCL is a heterogenous group in terms of clinical outcomes, morphology and cytogenetics [1]. Furthermore, it could arise de novo or progress from low grade B cell lymphomas such as follicular lymphoma and marginal zone lymphoma [1].

Of the low grade B cell lymphomas the commonest subtype in the Sri Lankan sample was follicular lymphoma. Patterns of low grade B cell lymphomas show significant geographical and ethnic variations. In the USA, SLL/CLL and follicular lymphoma are the two most common types of low grade lymphoma, whereas, in our sample, in India and in Pakistan the commonest type was follicular lymphoma and CLL/SLL was less common. Although follicular lymphoma is also common in the USA, molecular pathogenesis of follicular lymphoma in the US has been hypothesised to be distinct from those of Asian follicular lymphoma based on the differences in the frequencies of BCL 2 translocations in these geographic regions [14]. Incidence of CLL is four times higher in Caucasian Americans than in Asian Americans [2]. The prevalence of CLL/SLL remains low in all reviewed South Asian and East Asian countries further highlighting the genetic bias in white Caucasians. Mantle cell lymphoma, on the other hand, does not show a significant geographical variation in incidence, indicating that the pathogenesis of mantle cell lymphoma may be less affected by ethnicity associated genetic variations.

Among the East Asian countries, in South Korea, extranodal marginal zone lymphoma is the most common type of low grade lymphoma and the gastrointestinal tract is the most commonly affected site [11]. High prevalence of Helicobacter pylori gastritis in South Korea, which is a known aetiological agent for marginal zone lymphoma, has been indicated as the reason for this observation [11]. However, despite high prevalence of $H$. pylori infection, in Japan, the prevalence of follicular lymphoma is much higher than those of extranodal marginal zone lymphoma.
In our sample and in the reviewed countries there was very low frequuency of Burkitt lymphoma. Endemic Burkitt lymphoma is a classic, geographically exclusive B cell lymphoma which affects predominantly the equatorial African countries [1]. Burkitt lymphoma shows an aetiological association with Epstein - Barr virus and the geographical distribution pattern of Burkitts lymphoma overlaps with that of Plasmodium falciparum malaria, indicating a possible polymicrobial pathogenesis $[1,15$, 16]. On the other hand, non AIDS associated, sporadic Burkitt lymphoma, which occur in the rest of the world is rarer.

Similar to our finding, worldwide too, incidence of $\mathrm{T}$ cell lymphomas are much lower than B cell types. However, the frequency of mycosis fungoides, a primary $T$ cell lymphoma of skin, is higher in the Sri Lankan sample compared to other reviewed countries. This could be due to referral bias. The frequency of peripheral T cell lymphoma is also relatively higher in the Sri Lankan sample. The exact reason for this is not apparent. However, since peripheral $\mathrm{T}$ cell lymphoma is a diagnosis of exclusion of other specific T cell subtypes, non-availibility of immune markers for rarer sub types and molecular diagnosis in our institution could have contributed to this observation. In the countries we reviewed apart from Japan, Adult T cell leukaemia/lymphoma (ATLL) was rare. ATLL is confined to certain geographic regions such as South Western Japan, Caribean basin and parts of Central Africa [1]. This distribution pattern closely follows the prevalence pattern of HTLV -1 infection suggesting an aetiological link [1].

Compared to the reviewed countries relatively higher frequency of HL is observed in the Sri Lankan sample and Pakistan. Mixed cellular and nodular sclerosis types is the most common HL sub types in the reviewed countries. In the Sri Lankan sample, Pakistan and India the commonest HL sub type was mixed cellular, where as in the USA and Japan the commonest was nodular sclerosis type $[5,8,9,10]$.

The study had several limitations. The results are from a single tertiary care centre and therefore, there can be referral bias. Referrals from several regional skin clinics may have increased the numbers of mycosis fungoides. Non availability of immunomarkers and genetic markers to diagnose rare lymphoma subtypes may have lead to underdiagnosis of such sub types and increase the "not otherwise specified" groups.

\section{Conclusions}

In the Sri Lankan sample, $84.6 \%$ were NHLs and the rest were HLs. The most common sub types of NHL are diffuse large B cell lymphoma and follicular lymphoma. Of the HLs mixed cellular sub type was the commonest. The patterns of lymphoma subtypes in the Sri Lankan sample are comparable with the globally 
observed variations and similar to those observed in other South Asian countries. This study further highlights the geographic and ethnic variation of certain lymphoma subtypes.

\section{Acknowledgement}

Authors acknowledge the technical assistance by Mrs. S. M. Wickramasingha.

\section{Declaration of Interest}

There are no conflicts of interest.

\section{References}

1. Swerdlow SH, Campo E, Harris NL, Jaffe ES, Pilleri SA, Stein H, Thiele J, Vardiman JW (eds). World Health Organization classification of tumours of haematopoietic and lymphoid tissue. Lyon: IARC Press, 2008.

2. Morton LM. Dissecting lymphoma incidence to inform epidemiologic and clinical research. Leukemia \& Lymphoma 2013; 54: 1575-76.

3. Evens AM, Antillón M, Aschebrook-Kilfoy B, Chiu BCH. Racial disparities in Hodgkin's lymphoma: a comprehensive population-based analysis. Ann Oncol 2012; 23: 2128-37.

4. Clarke CA, Glaser SL. Changing incidence of non Hodgkin lymphomas in the United States. Cancer 2002; 94: 2015-23.

5. Morton LM, Wang SS, Devesa SS, Hartage P, Weisenburger DD, Linet MS,. Lymphoma incidence patterns by WHO subtype in the United States, 1992-2001. Blood 2006; 107: 265 -76.

6. Chiu BCH, Smith SM. Toward a global understanding of lymphoma: epidemiologic clues from the second most populous country. Leuk Lymphoma 2013; 54: 901-2.

7. Naresh KN, Srinivas V, Soman CS. Distribution of various subtypes of non-Hodgkin's lymphoma in India: A study of 2773 lymphomas using R.E.A.L. and WHO Classifications. Ann Oncol 2000; 11(Sup.I): 63-7.
8. Patkar N, Mehta J, Kulkarni B, Pande R, Advani S, Borges A. Immunoprofile of Hodgkin's lymphoma in India. Indian $J$ Cancer 2008; 45: 59-63.

9. Mushtaq S, Akhtar N, Jamal S, Mamoon N, Khadim T, Sarfaraz T, Waqar. A. Malignant Lymphomas in Pakistan According to WHO Classification of Lymphoid Neoplasms. Asian Pac J Cancer Prev 2008; 9: 229-32.

10. Aoki R, Karube K, Sugita Y, Nomura Y, Shimizu K, Kimura Y, Hashikawa K, Suefuji N, Kikuchi, Ohshima K. Distribution of malignant lymphoma in Japan: Analysis of 2260 cases, 2001-2006. Pathol Int 2008; 58: 174-82.

11. Sun Och Yoon, Cheolwon Suh, Dae Ho Lee, Hyun-Sook Chi, Chan Jeoung Park, Seong-Soo Jang, Hai-Rim Shin, Bong-Hee Park, Jooryung Huh. Distribution of lymphoid neoplasms in the Republic of Korea: Analysis of 5318 cases according to the World Health Organization classification. Am J Hematol 2010; 85: 760-4.

12. Yang QP, Zhang WY, Yu JB, Zhao S, Xu H, Wang WY, Bi CF, Zuo Z, Wang XQ, Huang J, Dai L, Liu WP. Subtype distribution of lymphomas in South West China: Analysis of 6,382 cases using WHO classification in a single institution. Diagn Pathol 2011; 6: 77.

13. Report: Cancer incidence data 2007. National Cancer Control Programme, Sri Lanka.

14. Biagi JJ, Seymour JF. Insights into the molecular pathogenesis of follicular lymphoma arising from analysis of geographic variation. Blood 2002; 99: 4265-75.

15. Rochford R, Cannon MJ, Moomann AM. Endemic Burkitt's lymphoma: a polymicrobial disease? Nat Rev Microbiol 2005; 3: 182-7.

16. Morrow RH Jr. Epidemiological evidence for the role of falciparum malaria in the pathogenesis of Burkitt's lymphoma. IARC Scientific Publications 1985; 60: 177-86.

17. Mondal SK, Mandal PK, Samanta TK, Chakaborty S, Roy SD, Roy S. Malignant lymphoma in Eastern India: A retrospective analysis of 455 cases according to World Health Organization classification. Indian J Med Paediatr Oncol 2013; 34: 242-6. 